OPEN ACCESS

Edited by:

Liangfeng Sun

Bowling Green State University,

United States

Reviewed by:

Yong $\mathrm{Li}$,

Anhui University of Technology, China

Woosung Kwon,

Sookmyung Women's University,

South Korea

Shashini Premathilaka,

University of Toledo, United States

*Correspondence:

Cui Liu

liucui@xjtu.edu.cn

Specialty section:

This article was submitted to

Nanoscience,

a section of the journal

Frontiers in Chemistry

Received: 11 September 2020 Accepted: 09 December 2020

Published: 22 January 2021

Citation:

Liu C, Zhang F, Hu J, Gao W and

Zhang M (2021) A Mini Review on pH-Sensitive Photoluminescence in

Carbon Nanodots.

Front. Chem. 8:605028

doi: 10.3389/fchem.2020.605028

\section{A Mini Review on pH-Sensitive Photoluminescence in Carbon Nanodots}

\author{
Cui Liu ${ }^{1 *}$, Fang Zhang ${ }^{1}$, Jiao $\mathrm{Hu}^{2}$, Wenhui Gao ${ }^{1}$ and Mingzhen Zhang ${ }^{1}$ \\ ${ }^{1}$ Department of Biophysics, School of Basic Medical Sciences, Institute of Medical Engineering, Xi'an Jiaotong University \\ Health Science Center, Xi'an, China, ${ }^{2}$ Hubei Key Laboratory of Environmental and Health Effects of Persistent Toxic \\ Substances, Institute of Environment and Health, Jianghan University, Wuhan, China
}

Carbon nanodots (C-dots) with $\mathrm{sp}^{2} / \mathrm{sp}^{3}$ framework and diameter of $<10 \mathrm{~nm}$ contain abundant functional groups or polymers on their surface. C-dots have attracted immense attention because of their unique optical properties, excellent biocompatibility, facile preparation, and low cost. With these merits, C-dots have been used in a wide range of applications including sensing, bioimaging, catalysis, and light-emitting devices. C-dots exhibit good optical properties, such as tunable emission wavelength, good photostability, nonblinking, up-conversion emission, etc. Of note, C-dots show intrinsic $\mathrm{pH}$-sensitive photoluminescence (PL), indicating their great potential for $\mathrm{pH}$ sensing, especially in biotic $\mathrm{pH}$ sensing. In this review, we systematically summarize the $\mathrm{pH}$-sensitive $\mathrm{PL}$ properties and the $\mathrm{pH}$-sensitive $\mathrm{PL}$ mechanism, as well as recent research progress of $\mathrm{C}$-dots in $\mathrm{pH}$ sensing. The current challenges of $\mathrm{pH}$-sensitive $\mathrm{C}$-dots and their future research focus are also proposed here. We anticipate this review might be of great significance for understanding the characteristics of $\mathrm{pH}$-sensitive $\mathrm{C}$-dots and the development of photoluminescent nanomaterials with $\mathrm{pH}$-sensitive properties.

Keywords: carbon nanodots, $\mathrm{pH}$-sensitive, photoluminescence, $\mathrm{pH}$ sensing, mechanism

\section{INTRODUCTION}

As a novel carbon nanomaterial, carbon nanodots (C-dots) have attracted extensive attentions because of their small particle size (generally $<10 \mathrm{~nm}$ ), wide source of raw materials, low cost, and excellent physical and chemical properties (Esteves da Silva and Gonçalves, 2011; Ding et al., 2014; Lim et al., 2015; Yuan et al., 2016; Liu et al., 2019). Unlike the previous carbon nanomaterials, C-dots are mainly composed of $\mathrm{sp}^{2} / \mathrm{sp}^{3}$ hybrid carbon with abundant functional groups or organic polymers on their surface. The C-dots mentioned here refer to carbon nanoparticles with carbon as the main constituent element, including carbon dots, carbon nanoparticles, graphene quantum dots, carbon quantum dots, and carbonized polymer dots in previous reports. The unique photoluminescence (PL) properties of C-dots including tunable emission, nonblinking, and excellent photostability enable them great potential in wide applications ranging from photoelectric device, fluorescence sensing, to bioimaging and nanomedicines (Hong et al., 2015; Lim et al., 2015; Yuan et al., 2016). Moreover, one of their most intriguing property is their $\mathrm{pH}-$ dependent PL. As the $\mathrm{pH}$ changes, the PL spectra or intensity of C-dots would change accordingly 
(Dong et al., 2010; Pan et al., 2010a,b; Qiao et al., 2010; Zhu et al., 2011, 2013). It is well-known that $\mathrm{pH}$ plays key role in industrial, agricultural, environmental, and biomedical fields (Wencel et al., 2014; Yin et al., 2015; Lei et al., 2017). It is of great significance for both scientific research and real-word applications to monitoring $\mathrm{pH}$ in disease diagnosis, environmental examination, food and beverage analysis, and so on (Wu et al., 2014; Mani et al., 2017). pH-sensitive nanoprobes based on organic dyes and nanocarriers have been developed to overcome the limitations of photobleaching, phototoxicity, and interference from background autofluorescence of traditional organic fluorescent dye. However, it is still difficult to achieve long-term and biological damage-free $\mathrm{pH}$ monitoring due to the poor biocompatibility and large particle size of organic dyes and nanocarriers. C-dots with small size, excellent photostability, and good biocompatibility have the potential to provide solutions for $\mathrm{pH}$ sensing in environmental, pharmaceutical, and especially in vivo medical applications.

In recent years, many synthetic methods have been developed to prepare $\mathrm{pH}$-sensitive $\mathrm{C}$-dots. Interestingly, although the synthesis methods, raw materials, structure, and morphology of C-dots are quite different, most $\mathrm{C}$-dots possess $\mathrm{pH}$-sensitive $\mathrm{PL}$ properties, despite their $\mathrm{pH}$ response behaviors are different (Figure 1) (Liu et al., 2007; Dong et al., 2010; Pan et al., 2010b; Kong et al., 2014; Lu et al., 2016; Hou et al., 2017; Sun et al., 2018; Pyne et al., 2019; Zhang M. et al., 2019). Mao et al. (Liu et al., 2007) prepared multicolor fluorescent $\mathrm{C}$-dots from candle soot. When the $\mathrm{pH}$ increased from 3 to 13, the PL intensity first increased and then decreased with the optimal intensity appearing under neutral conditions. Chi's group (Dong et al., 2010) also prepared C-dots with similar pH sensitivity by acidic oxidation of activated carbon. Pan et al. (2010b) reported blue-emitting C-dots with PL intensity increased as the $\mathrm{pH}$ increased. Yang's group (Lu et al., 2016) obtained white fluorescent C-dots by a hydrothermal method. The PL intensity of C-dots gradually decreased as the $\mathrm{pH}$ increased from 0 to 14 . Zhang $\mathrm{M}$. et al. (2019) obtained $\mathrm{N}$ - and S-codoped C-dots with long emission wavelength by solvothermal method using L-cysteine and $o$-phenylenediamine as raw materials. The PL intensity of C-dots was very strong when $\mathrm{pH}$ value was between 1.0 and 2.0 , but it suddenly decreased at $\mathrm{pH} \sim 3.0$ and exhibited almost no $\mathrm{PL}$ in $\mathrm{pH}$ ranging from 8.0 to 13.0 . It seems that the $\mathrm{PL} \mathrm{pH}$ sensitivity of C-dots largely depends on the synthesis method, reaction conditions, raw materials, etc. The PL mechanism of C-dots $\mathrm{pH}$ sensitivity is still unresolved, resulting in the difficulty to effectively control the $\mathrm{pH}$ sensitivity of C-dots, which greatly limits their practical application. Although there are many reviews focusing on the preparation, properties, and applications of C-dots, reviews discussing the $\mathrm{pH}$ sensitivity of C-dot are still lacking. In this review, we mainly focus on the PL mechanism of the $\mathrm{pH}$ sensitivity of $\mathrm{C}$-dots, including consistent and controversial conclusions. We hope that this review might provide a systematic understanding into the $\mathrm{pH}$-sensitive PL of $\mathrm{C}$-dots, thereby promoting the development of the application of $\mathrm{pH}$-sensitive C-dots.

\section{pH-DEPENDENT PL MECHANISMS}

The typical understanding of the mechanism of $\mathrm{pH}$-sensitive PL mainly focused on the deprotonation and protonation of acidic and basic groups in ground or excited states, which could change the property and the rate of transition processes, and finally affect the PL spectrum and intensity of the fluorophores (Valeur, 2001; Lakowicz, 2006). For example, the lowest excited singlet state $\left(n, \pi^{*}\right)$ of salicylaldehyde would undergo an intersystem crossing process quickly $\left(10^{-7}-10^{-9} \mathrm{~s}\right)$, leading to emission of phosphorescence rather than fluorescence. However, when the phenolic hydroxyl group is deprotonated in an alkaline solution or the carbonyl group is protonated in a concentrated acid solution, salicylaldehyde exhibits strong fluorescence rather than phosphorescence. This is because the lowest excited singlet state of salicylaldehyde is $\left(\pi, \pi^{*}\right)$ rather than the $(n$, $\left.\pi^{*}\right)$ when in the cationic or anionic forms. For C-dots, the structure is relatively complicated, mostly with graphite carbon or amorphous carbon as the main skeleton, and the surface is rich in carboxyl, hydroxyl, carbonyl, and other functional groups that may undergo protonation and deprotonation. This makes the pH-dependent PL mechanism of C-dots confusing and controversial. For example, Li et al. (2019) synthesized highly fluorescent C-dots by using tetrahydrofuran as carbon source via a hydrothermal treatment. As $\mathrm{pH}$ increased from 4 to 12 , the PL intensity decreased linearly. They believed that the $\mathrm{pH}$ sensitivity of $\mathrm{C}$-dots could be attributed to the reversible protonation and deprotonation of C-dots surface functional groups. However, there is no unified conclusion about the specific structure that should take responsibility to the $\mathrm{pH}$ sensitivity of C-dots. Currently, several mechanisms were proposed to interpret the $\mathrm{pH}$-sensitive $\mathrm{PL}$ of $\mathrm{C}$-dots (Figure 2), but hitherto there is still nothing that can match all the characteristics.

\section{CHANGE OF ENERGY LEVEL}

The $\mathrm{pH}$ sensitivity of $\mathrm{C}$-dots originating from the protonation and deprotonation of oxygen-containing groups on the surface, which could change the energy level of C-dots, is one of the most comprehensively accepted mechanism. Wang et al. (2018) prepared C-dots with colorimetric and fluorescent $\mathrm{pH}$-sensitive property. The PL peak of C-dots was at $630 \mathrm{~nm}$ in $\mathrm{pH}$ ranging from 1 to 6 and blue shifted to $590 \mathrm{~nm}$ with intensity slightly decreased under $\mathrm{pH}$ ranging from 7 to 14 . They claimed that as $\mathrm{pH}$ increased, the $-\mathrm{COOH}$ and $-\mathrm{OH}$ changed to $-\mathrm{COO}^{-}$ and $-\mathrm{O}^{-}$, resulting in the change of $\mathrm{PL}$ of $\mathrm{C}$-dots. However, they did not explain how the deprotonation of $\mathrm{COOH}$ and $\mathrm{OH}$ affected the PL of C-dots. As proposed by Pan et al. (2010a) the $\mathrm{PL}$ of $\mathrm{C}$-dots originated from zigzag sites. When the $\mathrm{pH}$ value of the environment decreased, the carbonyl oxygen of the zigzag sites of $\mathrm{C}$-dots underwent a protonation process, and the structure of the triplet carbene was destroyed, resulting in the PL intensity decrease. Jin's group (Sui et al., 2016) investigated ultrafast carrier relaxation dynamics in C-dots under different $\mathrm{pH}$ by femtosecond transient absorption spectra. They claimed that the distribution of $\pi$ electron cloud density between the 

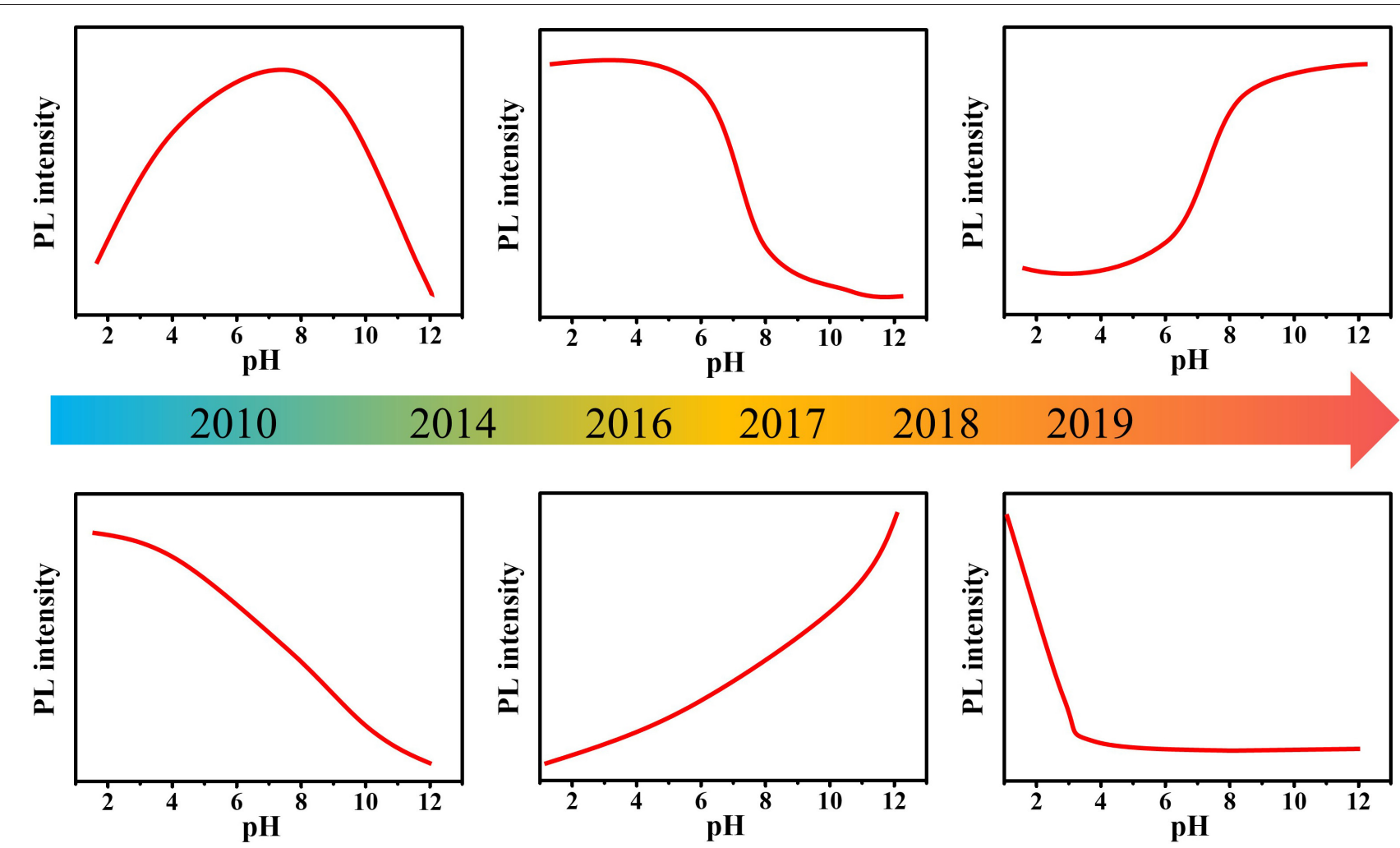

$2014 \quad 2016 \quad 2017 \quad 2018$

2019
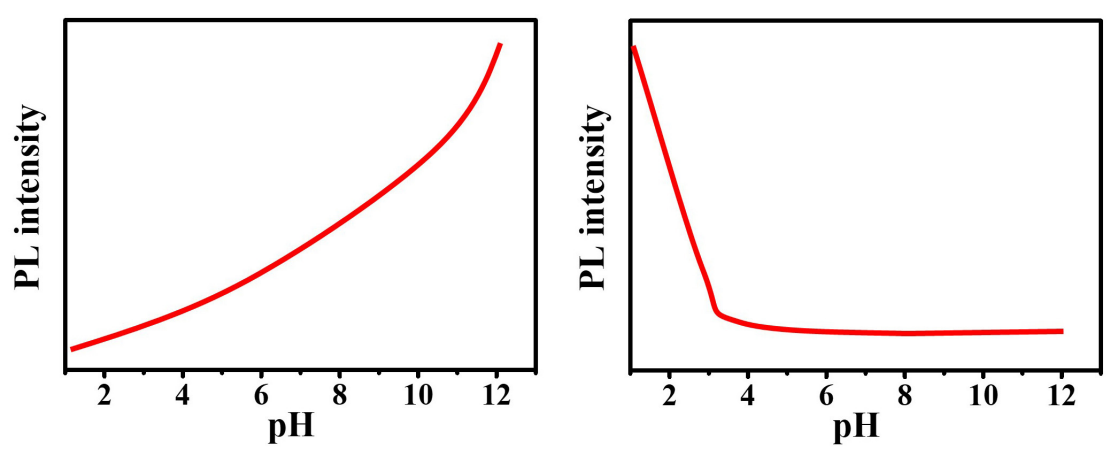

FIGURE 1 | Timeline showing the $\mathrm{pH}$-sensitive C-dots in the review.

carbon backbone and surface states would be changed by the deprotonation of carboxyl at higher $\mathrm{pH}$. Therefore, the excited electrons in alkaline environment could be more easily trapped by surface within $1 \mathrm{ps}$, leading to the increase of PL intensity. Shi et al. (2016) prepared blue fluorescent C-dots with the $\mathrm{PL}$ intensity significantly increased as $\mathrm{pH}$ increased from 3 to 11. They believed that the increase of PL intensity of C-dots was induced by the deprotonation of carboxyl groups, which promoted the formation of delocalized $\pi$ bonds and increase of $n$ electrons. Meanwhile, Dutta Choudhury et al. (2017) observed that the PL intensity of C-dots gradually increased as the $\mathrm{pH}$ increased from 1 to 6 and then decreased at higher $\mathrm{pH}$ along with a significant PL red shift. The PL decay curves of C-dots at $\mathrm{pH} 2.7$ and 9.5 were recorded under excitation of 374 and $400 \mathrm{~nm}$. The lifetime of C-dots under higher $\mathrm{pH}$ was longer than that under lower $\mathrm{pH}$ value, which was more pronounced under the longer wavelength excitation, confirming that these are different between the optical characteristics of emissive species in basic and acidic conditions. Combining structural characterization results, they claimed that the carboxyl group was decoupled from the emission sites and therefore did not affect the energy level of C-dots, but it would cause intramolecular or the intermolecular hydrogen bond and lead to strong vibrational coupling of the $\mathrm{OH}$ functional groups in the surface state of C-dots, which possibly leads to energy level broadening and accordingly to the occurrence of broad bands in the absorption spectra of C-dots at low $\mathrm{pH}$. When the $\mathrm{pH}$ increases from 2.5 to 7.9 , the carboxyl group gradually underwent a proton dissociation process, the effect of hydrogen bonds was gradually eliminated, and the PL intensity increases without PL spectrum change, whereas the phenolic hydroxyl group was coupled with emission sites, and its deprotonation would create a new surface state in C-dots with a lower band gap. When the $\mathrm{pH}$ value gradually increased from 7.9, the carboxyl group has been in deprotonation state, whereas the phenolic hydroxyl group gradually underwent a deprotonation process, resulting in a decrease in PL intensity with the spectrum redshifting. However, Basu and Mandal (2019) have the opposite opinion. They performed time-resolved PL emission to study the photophysics of $\mathrm{C}$-dots in different $\mathrm{pH}$ solutions. As they proposed, using $\lambda_{\text {ex }} \leq 350 \mathrm{~nm}$, the core and high-energy edge states were excited, producing hole-electron excitonic charge carriers without any PL emission. The surface fluorophores and low-lying edge states could be excited at excitation wavelength $\lambda_{\text {ex }} \sim 375 \mathrm{~nm}$, inducing broad PL, which was dependent on the $\mathrm{pH}$ and excitation wavelength. At $\mathrm{pH} \geq 5$, which marks the deprotonation of $-\mathrm{COOH}$, the edge state was quenched by the carboxylate anion. Although it is believed that the protonation and deprotonation of oxygen-containing groups would have a great impact on the energy level of C-dots, which significantly 


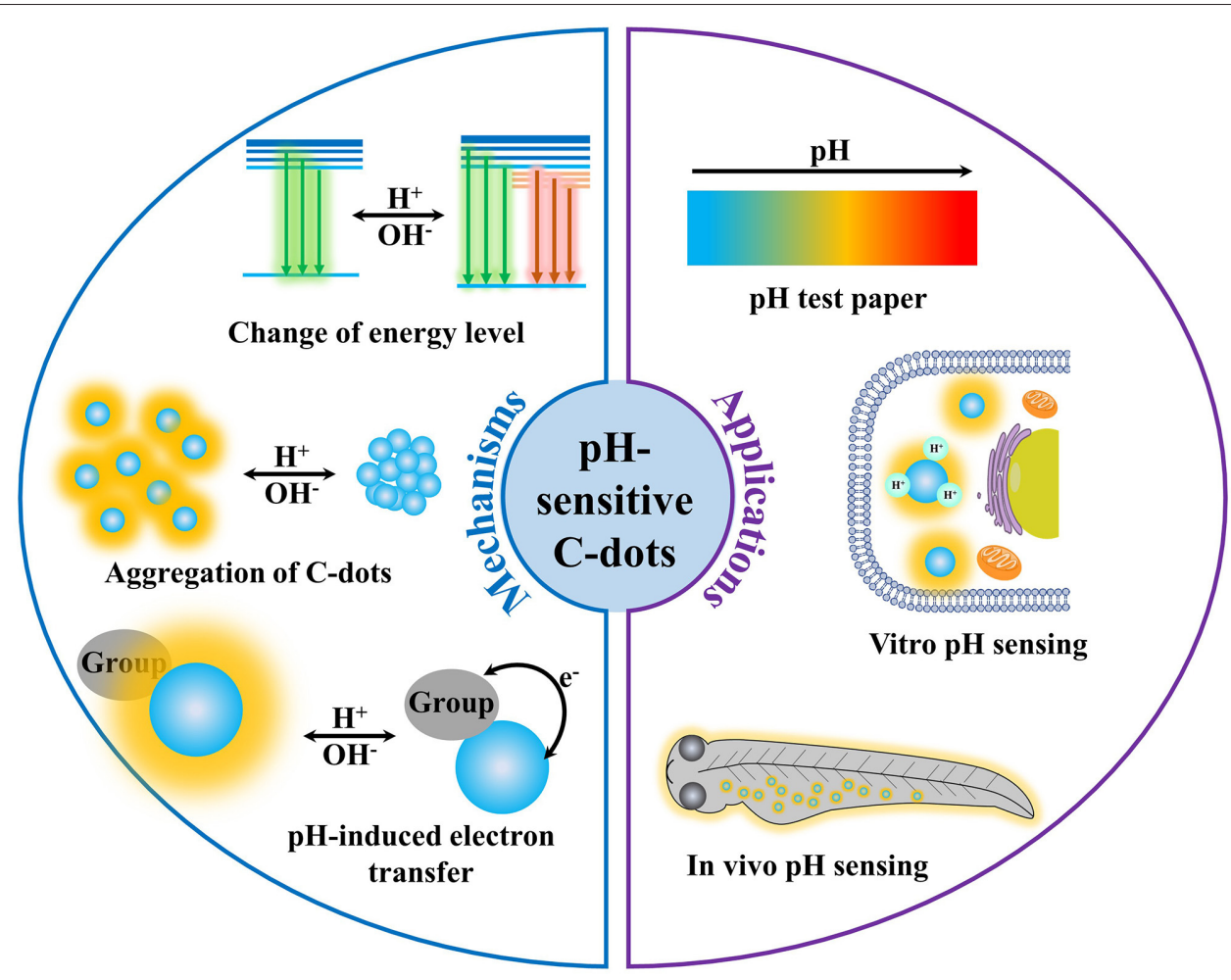

FIGURE 2 | The mechanisms and applications of $\mathrm{pH}$-sensitive photoluminescent C-dots.

change their fluorescence properties, these are often controversial on the contributions of specific functional groups on $\mathrm{pH}$ sensitive properties of C-dots.

In addition, the energy level change caused by $\mathrm{H}^{+} / \mathrm{OH}^{-}$is also considered to be one of the mechanisms of $\mathrm{pH}$-sensitive $\mathrm{PL}$ in C-dots. Kong et al. (2014) reported pH-sensitive C-dots with different surface modifications. In their hypothesis, the absorbed $\mathrm{OH}^{-}$could passivate the surface defects of C-dots and create a surface modified protective shell layer, which make C-dots isolated and lowered down the nonradiative recombination rate, leading to the increase of PL intensity and blue-shifting of emission peak, whereas $\mathrm{H}^{+}$could destroy the protective shell passivated by $\mathrm{OH}^{-}$, create new surface defects on C-dots, and enlarge the size of $\mathrm{C}$-dots by prolonging the length of conjugated chain, resulting in PL quenching and red-shifting of emission peak. Moreover, Guo et al. (2018) and Liu et al. (2017) also attributed the $\mathrm{pH}$-dependent $\mathrm{PL}$ to the protective shell formed by the passivation of absorbed $\mathrm{OH}^{-}$on the surface detects of C-dots. Nevertheless, Jia et al. (2012) believed that the protonation and deprotonation of the carboxyl groups on the surface of C-dots might induce electrostatic doping/charging to the C-dots and shift the Fermi level. Tan et al. (2018) also believed that the deprotonation of oxygen-containing functional groups on the surface of C-dots at high $\mathrm{pH}$ leaded to the increase of surface negative charge, which caused the shift of Fermi level and restrained the electron transition of some emission centers by occupying the energy levels. Zhao et al. (2019) believed that the $\mathrm{H}$-bond could lead to the strong vibration coupling of $\mathrm{OH}$ at lower $\mathrm{pH}$, which caused the energy level broadening and increase the conformational rigidity of $\mathrm{C}$-dots, bringing about the strong PL intensity. However, alkaline conditions could eliminate $\mathrm{H}$-bonding effect through the deprotonation progress, resulting in the decrease of vibrational coupling and more discrete energy levels, giving rise to the decrease of PL intensity of C-dots. The C-dots reported by $\mathrm{Hu}$ et al. (2017) exhibited two emission centers at 550 and $630 \mathrm{~nm}$ attributing to $\mathrm{N}$-state and P-state, respectively. As $\mathrm{pH}$ varied from 2 to 12 , the intensity of peak at $550 \mathrm{~nm}$ was decreased significantly, whereas the intensity of peak at $630 \mathrm{~nm}$ exhibited continuous enhancing behavior, producing a linear relationship between the PL intensity ratios of the two emission peaks $\left(I_{550} / I_{630}\right)$ and $\mathrm{pH}$. As they claimed, the protonation of amine groups would dismiss the unpaired electrons and reduce the electron density in CDs, resulting in the decrease of PL intensity with blue shift of PL peak of $\mathrm{N}$-state. The $\mathrm{pH}$ variation had little effects on the energy level of the P-state; the peak at $630 \mathrm{~nm}$ remained stable over a wide $\mathrm{pH}$ range of 2 to 12 . The combination of P-related groups with $\mathrm{OH}^{-}$radicals at high $\mathrm{pH}$ would enhance the density of the P-state, promoting the emission at $630 \mathrm{~nm}$. 


\section{AGGREGATION OF C-DOTS}

There are also many researchers who believed that the $\mathrm{pH}$ sensitivity of C-dots was caused by the $\mathrm{pH}$ induced aggregation of C-dots. Xu et al. (2015) studied the reversible photophysical properties of C-dots at different $\mathrm{pH}$. The UV-vis absorption and $\mathrm{PL}$ spectra of the $\mathrm{C}$-dots exhibited reversible changes as the $\mathrm{pH}$ varied in the range of 3 to 13 . As $\mathrm{pH}$ increased from 3 to 13 , the absorption peak centered at $280 \mathrm{~nm}$ was red-shifted to $285 \mathrm{~nm}$, whereas the absorption band at $220 \mathrm{~nm}$ gradually became ill-defined and finally disappeared. As the $\mathrm{pH}$ switched from 3 to 7 , the emission peak of C-dots was red-shifted $\sim 20 \mathrm{~nm}$ with increase in PL intensity. When the $\mathrm{pH}$ increased from 7 to 13 , the PL intensity decreased, but the emission peak was stable. As the $\mathrm{pH}$ was restored to 3 , both of the absorption and emission bands recovered their original shapes. Moreover, both of the optimal emission and excitation peaks of C-dots were redshifted as the $\mathrm{pH}$ increased from 2 to 13 . They considered that under acidic conditions, the $\mathrm{C}$-dots gathered into lager particles rapidly, and oxygen-containing functional groups on the surface were slowly oxidized, leading to the PL decrease with blueshifting. While under alkaline conditions, the structural tautomer occurred very fast, and the hydrogenation/deoxygenation process happened slowly, resulting in PL intensity decrease. Wang et al. (2015) proposed that as the $\mathrm{pH}$ increased, the aggregation C-dots appeared because of noncovalent molecular interactions, such as hydrogen bonds between the carboxyl groups, resulting in PL quenching. Mondal et al. (2019) reported blue emissive C-dots with PL intensity increase as $\mathrm{pH}$ increased from 1 to 7 . They attributed the PL quenching in lower $\mathrm{pH}$ to the aggregation of C-dots induced by the protonation of carboxyl groups. Sun et al. (2018) explained pH sensitivity of C-dots by zeta potential and transmission electron microscopy (TEM) measurement. The zeta potentials of C-dots were $\sim 17 \mathrm{mV}$ at $\mathrm{pH} 4-5$. As $\mathrm{pH}$ increased from 5 to 11 , the zeta potentials decreased from 17 to $-12 \mathrm{mV}$, along with the aggregation of C-dots shown in TEM images. So, they believed that under lower $\mathrm{pH}$ conditions, the protonation of carboxyl of surface of C-dots and noncovalent molecular interaction, such as hydrogen bonds, induced the aggregation of $\mathrm{C}$-dots, resulting in PL quenching.

In addition to carboxyl groups, amides, amino groups, and phosphorus-containing functional groups may also undergo protonation and deprotonation, causing aggregation of the C-dots. Liu's group (Ye et al., 2019) attributed the PL pH response of $\mathrm{C}$-dots to the aggregation-disaggregation induced by the deprotonation and protonation of the amino group on the surface of C-dots. Under alkaline conditions, because of the formation of intermolecular hydrogen bond, the C-dots might aggregate and result in PL quenching. On the other hand, Ren's group (Chen et al., 2019) believed that it might be due to the protonation of the amine groups on the surface of $\mathrm{C}$-dots under strong acid conditions, leading to the aggregation of the C-dots and quenching their PL. At the same time, the new surface state $\left(-\mathrm{NH}_{3}^{+}\right)$would cause a slight blue shift in the emission spectrum as the $\mathrm{pH}$ rises. In fact, whether the protonation or the deprotonation of amino leads to the aggregation of the C-dots depends on their structure and electric charge. The
C-dots often contain other negatively charged functional groups besides the amino. The $\mathrm{C}$-dots with high content of amino have a positive charged surface and are stable under acidic conditions. When under alkaline conditions, the deprotonation of amino groups would result in the decrease of the amount of charge of C-dots and cause the aggregation. In contrast, the $\mathrm{C}$-dots with less amino have a negatively charged surface. Under acidic conditions, the amino group is protonated, reducing the amount of charge of C-dots, and the aggregation of C-dots occurs. Su et al. (2019) synthesized nitrogen- and phosphoruscodoped C-dots. The C-dots exhibited blue fluorescent emission and green room temperature phosphorescence (RTP). Both of the fluorescence and RTP of C-dots exhibited $\mathrm{pH}$ sensitivity. The fluorescence decreased as $\mathrm{pH}$ increased from 9.15 to 13.55 , whereas the RTP was more sensitive to $\mathrm{pH}$ in a wider linear ranging from 2.29 to 13.55 . As proposed by the authors, the $\mathrm{C}$-dots and phosphoric acid were connected by C-O-P, C-P, and $\mathrm{N}-\mathrm{P}$ bonds. The protonation and deprotonation of the $\mathrm{P}-\mathrm{O}$ bond mainly determined the fluorescence and phosphorescence $\mathrm{pH}$ sensitivity. Under acidic conditions, there were $\mathrm{P}-\mathrm{O}-\mathrm{H}$ groups on the surface of $\mathrm{C}$-dots, and thus intramolecular and intermolecular hydrogen bonds are formed between $\mathrm{P}=\mathrm{O}$ and $\mathrm{OH}$, which ensures the stability of C-dots. After adding $\mathrm{NaOH}$, the deprotonation of the $\mathrm{P}-\mathrm{O}-\mathrm{H}$ bond happened, resulting in the dissociated of hydrogen bonds. Therefore, the steady surface state changed, and formation of crystal nucleus occurred. As the concentration of $\mathrm{OH}^{-}$increased, the crystal nuclei begin to grow and cause the $\mathrm{C}$-dots to gradually precipitated, resulting in the concentration of C-dots decrease in the solution. Consequently, both the RTP and fluorescence of C-dots ultimately decreased.

\section{pH-INDUCED ELECTRON TRANSFER}

In addition to changing the energy level, protonation, and deprotonation of functional groups could also cause electron transfer between functional group and emission site of C-dots as pH changes, thereby resulting in the PL change. Lv et al. (2019) reported the design and fabrication of $\mathrm{pH}$-sensitive $\mathrm{C}$-dots with strong orange light emission. They attributed the $\mathrm{pH}$ sensitivity of C-dots to the protonation of amino on the surface of C-dots, which enhanced the intramolecular electron transfer ability between $-\mathrm{NH}_{3}^{+}$and C-dots, giving rise to the PL quenching. As the $\mathrm{pH}$ value reduced from 7.0 to 3.0, the amino groups gradually underwent a protonation process, resulting in the decrease of PL intensity of C-dots with a linear relationship in $\mathrm{pH}$ ranging from 6.5 to 3.0, whereas in the $\mathrm{pH}$ value range of 7.0-9.0, the PL intensity of C-dots changed negligibly because of the low protonation of the amino group. Liu H. et al. (2019) prepared fluorescent ratiometric $\mathrm{pH}$-sensitive C-dots. As $\mathrm{pH}$ increased from 2.99 to 10.02, the absorption of C-dots was blue-shifted from 510 to $433 \mathrm{~nm}$. The absorption ratio $\left(I_{433} / I_{510}\right)$ of C-dots exhibited good linearity with the $\mathrm{pH}$ in the range of 5.4 to 8.0, and the pKa value was calculated to be 6.89. At the same time, the PL intensity of C-dots increased gradually with PL spectrum blue-shifting from 625 to $565 \mathrm{~nm}$. They attributed the shift of PL spectra to the protonation and deprotonation of the 
pyridinic group, which could alter the internal charge transfer (ICT) process of C-dots. Meanwhile, green-emissive C-dots with $\mathrm{pH}$ sensitivity were synthesized by Wang Q. et al. (2019) via using $\mathrm{m}$-phenylenediamine as the carbon source in the presence of strong $\mathrm{H}_{2} \mathrm{SO}_{4}$. The PL intensity of $\mathrm{C}$-dots decreased obviously without any change in $\mathrm{PL}$ emission spectra as $\mathrm{pH}$ increased from 3.0 to 12.0 . There were no obvious changes in UV-vis spectra and average sizes (according to the TEM images) of C-dots with $\mathrm{pH}$ values increasing from 6.0 to 10.0 . Therefore, they excluded the aggregation-induced $\mathrm{PL}$ quenching and attributed the $\mathrm{pH}$ sensitive PL of C-dots to the photoinduced electron transfer process from the electron lone pair in amino group to the $\mathrm{C}$-dots. At high $\mathrm{pH}$, the excited electrons of C-dots can transition from the highest occupied molecular orbital (HOMO) to the lowest unoccupied molecular orbital. Because of the fact that the HOMO energy level of amino group is higher than that of C-dots, the ground state electrons of the amino group could jump to the $\mathrm{HOMO}$ of C-dots, resulting in significant PL quenching.

\section{APPLICATIONS OF pH-SENSITIVE C-DOTS}

In the past decade, C-dots with superior optical properties, low toxicity, good dipersibility, and low cost have been used in detection, bioimaging, catalysis, optoelectronics devices, etc. (Baker and Baker, 2010; Esteves da Silva and Gonçalves, 2011; Li et al., 2012; Shen et al., 2012; Ding et al., 2014; Hola et al., 2014; Wang et al., 2014; Lim et al., 2015) Particularly, C-dots with the $\mathrm{pH}$ sensitivity have significant potential in $\mathrm{pH}$ sensing (Figure 2). Chen's group (Wang et al., 2019) prepared green fluorescent $\mathrm{C}$-dots by solvothermal method using $\mathrm{m}$-diaminobenzoic acid as the carbon sources. The PL intensity of C-dots increased as $\mathrm{pH}$ increased from 4.5 to 12 . Because the PL intensity was linearly correlated with $\mathrm{pH}$ ranging from 6.0 to 9.0 , the C-dots were applied to measure the $\mathrm{pH}$ of eight kinds of mineral water samples with $\mathrm{pH}$ ranging from 5.9 to 8.1 . The $\mathrm{pH}$ values measured by $\mathrm{pH}$-sensitive $\mathrm{C}$-dots were consistent with that measured by a $\mathrm{pH}$ meter, proving the feasibility of $\mathrm{pH}$ sensors based on C-dots. Lü's group (Zhang T. Y. et al., 2019) synthesized tricolor emission C-dots via hydrothermal method using 5amino-1,10-phenanthroline and citric acid. At pH 1, the PL of $\mathrm{C}$-dots was relatively weak with a broad peak at $510 \mathrm{~nm}$. When the $\mathrm{pH}$ increased to 2 , the $\mathrm{C}$-dots showed three strong emission peaks at 440,510 , and $620 \mathrm{~nm}$. As the $\mathrm{pH}$ increased, the PL intensity of the three emission peaks gradually decreased with different extents. The $\mathrm{C}$-dots were used as $\mathrm{pH}$ test paper to detect the $\mathrm{pH}$ value ranging from 1 to 14 . The C-dots-based $\mathrm{pH}$ test paper showed bright green at $\mathrm{pH} 1$ and gradually turned gray as the $\mathrm{pH}$ value increased from 1 to 8 . Then, the color of the test paper changed from blue to purple when the $\mathrm{pH}$ increased from 8 to 13 and changed to yellow when the $\mathrm{pH}$ was 14 . The color change from bright green to blue purple was very obvious. The $\mathrm{pH}$ value of the solution can be clearly distinguished with the naked eye thorough the color of the $\mathrm{pH}$ test paper. Besides, A novel orange-emissive C-dots were synthesized by Zhou's group (Yang et al., 2019) via microwave-assisted heating of 1,2,4triaminobenzene and urea aqueous solution. The C-dots showed unique colorimetric and fluorescence response to $\mathrm{pH}$ changes. Because the PL intensity of C-dots exhibited a sigmoidal logistic relationship with $\mathrm{pH}$ over a wound-relevant $\mathrm{pH}$ range (Pan et al., 2010a,b; Qiao et al., 2010; Hong et al., 2015; Liu et al., 2019), medical cotton cloth was chosen to immobilize C-dots through hydrogen bond interaction, producing a novel $\mathrm{pH}$ indicator (i.e., C-dots-coated medical cotton cloth) with PL emission at $560 \mathrm{~nm}$. The novel $\mathrm{pH}$ indicator not only has excellent biocompatibility and drug compatibility, but also has excellent leachability and high reversibility, contributing to its safety and reliability for wound $\mathrm{pH}$ sensing. Importantly, the use of C-dots-coated cloth to detect $\mathrm{pH}$ would not be disturbed by blood contamination and long-term storage, providing wound $\mathrm{pH}$ monitoring and long-term observations through visual response and quantitative determination in the case of blood contamination.

Meanwhile, because of their good biocompatibility, small size, and photostability, the $\mathrm{pH}$-sensitive $\mathrm{C}$-dots also were applied for $\mathrm{pH}$ sensing in organelle, cell, tissue, and living animals (Liu et al., 2018; Xia et al., 2018; Zhang et al., 2018; Ye et al., 2019; Zhang T. Y. et al., 2019). Huang's group (Zhang et al., 2018) prepared emerald emissive C-dots using the functional preservation strategy by simply mixing p-benzoquinone and ethanediamine at room temperature. The C-dots with abundant protective amino groups exhibited good hydrophilicity, which ensures good lysosomal targeting specificity and sensitive and selective detection of lysosomal $\mathrm{pH}$ changes in vitro. The PL intensity of CDs decreased as $\mathrm{pH}$ decreased from 7.40 to 3.00 with good linearity in the $\mathrm{pH}$ range of 4.00-5.80, which was beneficial for lysosome $\mathrm{pH}$ sensing. The $\mathrm{C}$-dots were used to monitor $\mathrm{pH}$ changes in lysosomal during apoptosis of living cells. After incubation for $80 \mathrm{~min}$, a strong green PL of C-dots was observed in normal A549 cells. However, when A549 cells were treated with dexamethasone, which can induce apoptosis in living cells due to proton leakage, their PL intensity showed time-dependent decrease, suggesting that the bright green C-dots can monitor the $\mathrm{pH}$ changes of lysosomal in real time. Liu's group (Ye et al., 2019) fabricated two photofluorescent C-dots, which showed a $\mathrm{pH}$-sensitive red fluorescence in $\mathrm{pH}$ ranging from 1.0 to 9.0 with a linear range of 3.5 to 6.5 , which is desirable for tracking the $\mathrm{pH}$ value in living cells. The MCF-7 cells were selected to verify the capability of C-dots to monitor the intracellular $\mathrm{pH}$ fluctuation. When the intracellular $\mathrm{pH}$ increases from 4.0 to 8.0 , the red fluorescence of C-dots in cells decreased obviously. Furthermore, they examined the $\mathrm{pH}$ imaging of renal tissue slice and tumors with the $\mathrm{C}$-dots. The renal tissue slice of the mouse treated with acetazolamide, which can neutralize the acid in tissue, exhibited apparently weaker fluorescence than that of the normal mouse. Because of tumor tissues having an acidic extracellular $\mathrm{pH}(\mathrm{pH}$ 6.5-6.8), the tumor tissue slice showed a stronger fluorescence than normal muscle tissue $(\mathrm{pH}$ 7.4). Moreover, the $\mathrm{pH}$-sensitive $\mathrm{C}$-dots were administered to zebrafish in buffer solution with different $\mathrm{pH}$ ranging from 4.0 to 8.0. The zebrafish exhibited extremely weak emission under alkaline conditions ( $\mathrm{pH} \mathrm{8.0)}$ and a strong red fluorescence signal under acidic conditions ( $\mathrm{pH} 4.0)$. All these reports show that $\mathrm{C}$-dots with $\mathrm{pH}$-sensitive PL exhibit significant promise for the monitoring of $\mathrm{pH}$ changes in living cells, tissues, and living 
animals, proving they can serve as a useful research tool for biomedical studies.

\section{CONCLUSIONS, CHALLENGES, AND PERSPECTIVE}

Since the first discovery in the separation of single-walled carbon nanotubes in 2004 (Xu et al., 2004), C-dots have quickly caused much attention because of the unique PL properties, excellent stability, good biocompatibility, and low biological toxicity. In the past years, the applications of C-dots have rapidly penetrated from materials science to biomedicine, catalysis, energy, environment, and other fields. Although the development of C-dots is so fast, research in various aspects is still in its infancy. The $\mathrm{pH}$ sensitivity of $\mathrm{C}$-dots has gradually attracted widespread attention in recent years. In addition, because of the small particle size, good biocompatibility, and photostability, C-dots show great potential in $\mathrm{pH}$ sensing, especially in intracellular and in vivo $\mathrm{pH}$ sensing. In this review, we outline the $\mathrm{pH}$ sensitivity property, the $\mathrm{pH}$-sensitive $\mathrm{PL}$ mechanism, and the latest application research progress of C-dots. Although $\mathrm{C}$-dots overcome many of the shortcomings of traditional $\mathrm{pH}$ probes, there are still some exciting challenges: (1) the PL $\mathrm{pH}$ sensitivity and response range of C-dots reported cannot meet the requirement of practical applications. Development of synthetic methods to prepare $\mathrm{pH}$-sensitive C-dots with desired $\mathrm{pH}$ response range and sensitivity is a key issue that needs to be solved urgently. (2) The $\mathrm{pH}$-sensitive mechanism of C-dots PL is mostly based on the structures on the C-dots surface, which may have prototropic equilibrium or interact with $\mathrm{H}^{+} / \mathrm{OH}^{-}$. However, the specific groups or structures that

\section{REFERENCES}

Baker, S. N., and Baker, G. A. (2010). Luminescent carbon nanodots: emergent nanolights. Angew. Chem. Int. Ed. 49, 6726-6744. doi: 10.1002/anie.200906623

Basu, N., and Mandal, D. (2019). Time-resolved photoluminescence of $\mathrm{pH}-$ sensitive carbon dots. Carbon 144, 500-508. doi: 10.1016/j.carbon.2018.12.056

Chen, X., Bai, J., Ma, Y., Yuan, G., Mei, J., Zhang, L., and Ren, L. (2019). Multifunctional sensing applications of biocompatible Ndoped carbon dots as $\mathrm{pH}$ and $\mathrm{Fe}^{3+}$ sensors. Microchem. J. 149:103981. doi: 10.1016/j.microc.2019.103981

Ding, C., Zhu, A., and Tian, Y. (2014). Functional surface engineering of C-dots for fluorescent biosensing and in vivo bioimaging. Acc. Chem. Res. 47, 20-30. doi: 10.1021/ar400023s

Dong, Y. Q., Zhou, N. N., Lin, X. M., Lin, J. P., Chi, Y. W., and Chen, G. N. (2010). Extraction of electrochemiluminescent oxidized carbon quantum dots from activated carbon. Chem. Mater. 22, 5895-5899. doi: 10.1021/cm1018844

Dutta Choudhury, S., Chethodil, J. M., Gharat, P. M., P., and K, P., Pal, H. (2017). $\mathrm{pH}$-elicited luminescence functionalities of carbon dots: mechanistic insights. J. Phys. Chem. Lett. 8, 1389-1395. doi: 10.1021/acs.jpclett.7b00153

Esteves da Silva, J. C. G., and Gonçalves, H. M. R. (2011). Analytical and bioanalytical applications of carbon dots. Trac Trends Anal. Chem. 30, 1327-1336. doi: 10.1016/j.trac.2011.04.009

Guo, X., Zhu, Y., Zhou, L., Zhang, L., You, Y., Zhang, H., and Hao, J. (2018). A facile and green approach to prepare carbon dots with $\mathrm{pH}$-dependent fluorescence for patterning and bioimaging. RSC Advances. 8, 38091-38099. doi: 10.1039/C8RA07584K should take responsibility to $\mathrm{pH}$ sensitivity are still unrevealed. The understanding of the effect of a specific structure or group to the $\mathrm{pH}$ sensitivity of $\mathrm{C}$-dot is often controversial. In order to address this issue, it is vital to develop a more specific method to quantitatively regulate specific groups on the surface of $\mathrm{C}$-dots to study the origin of $\mathrm{pH}$-sensitive properties of $\mathrm{C}$-dots, clarify the $\mathrm{pH}$-sensitive fluorescence mechanism, and further propose practical methods for regulating the $\mathrm{pH}$-sensitive fluorescence properties of C-dots. (3) The structures of C-dots synthesized by different raw materials or different methods are very different from each other. When investigating the $\mathrm{pH}$ sensitivity PL mechanism of C-dots, it is necessary to consider them differently. The structure contributing to the $\mathrm{pH}$ sensitivity may be various for C-dots with different structures because their PL mechanisms are different. Solving these issues will greatly promote the application of the $\mathrm{pH}$-sensitive $\mathrm{C}$-dots.

\section{AUTHOR CONTRIBUTIONS}

$\mathrm{CL}$ wrote the paper. FZ, JH, WG, and $\mathrm{MZ}$ revised the paper. All authors contributed to the article and approved the submitted version.

\section{FUNDING}

This work was supported by the National Natural Science Foundation of China (21805021 and 21804103), China Postdoctoral Science Foundation (2020M683449 and 2018M631057), the Natural Science Foundation of Shaanxi province (2020JQ-087 and 2020JQ-095), the Young Talent Support Plan of Xi'an Jiaotong University (YX6J001), and the Fundamental Research Funds for the Central Universities.

Hola, K., Zhang, Y., Wang, Y., Giannelis, E. P., Zboril, R., and Rogach, A. L. (2014). Carbon dots-emerging light emitters for bioimaging, cancer therapy and optoelectronics. Nano Today 9, 590-603. doi: 10.1016/j.nantod.2014. 09.004

Hong, G., Diao, S., Antaris, A. L., and Dai, H. (2015). Carbon nanomaterials for biological imaging and nanomedicinal therapy. Chem. Rev. 115, 10816-10906. doi: 10.1021/acs.chemrev.5b00008

Hou, P., Yang, T., Liu, H., Li, Y. F., and Huang, C. Z. (2017). An active structure preservation method for developing functional graphitic carbon dots as an effective antibacterial agent and a sensitive $\mathrm{pH}$ and $\mathrm{Al}$ (III) nanosensor. Nanoscale. 9, 17334-17341. doi: 10.1039/C7NR05539K

Hu, S., Meng, X., Tian, F., Yang, W., Li, N., Xue, C., Yang, J., and Chang, Q. (2017). Dual photoluminescence centers from inorganic-salt-functionalized carbon dots for ratiometric pH sensing. J. Mater. Chem. C. 5, 9849-9853. doi: 10.1039/C7TC03266H

Jia, X., Li, J., and Wang, E. (2012). One-pot green synthesis of optically $\mathrm{pH}$-sensitive carbon dots with upconversion luminescence. Nanoscale. 4, 5572-5575. doi: 10.1039/c2nr31319g

Kong, W., Wu, H., Ye, Z., Li, R., Xu, T., and Zhang, B. (2014). Optical properties of $\mathrm{pH}$-sensitive carbon-dots with different modifications. J. Lumines. 148, 238-242. doi: 10.1016/j.jlumin.2013.12.007

Lakowicz, J. R. (2006). Principles of Fluorescence Spectroscopy. New York, NY: Springer Science+Business Media.

Lei, Y., Song, B., van der Weijden, R. D., Saakes, M., and Buisman, C. J. N. (2017). Electrochemical induced calcium phosphate precipitation: importance of local pH. Environ. Sci. Technol. 51, 11156-11164. doi: 10.1021/acs.est.7b03909 
Li, C., Zhang, X., Zhang, W., Qin, X., and Zhu, C. (2019). Carbon quantum dots derived from pure solvent tetrahydrofuran as a fluorescent probe to detect $\mathrm{pH}$ and silver ion. J. Photochem. Photobiol. A Chem. 382:111981. doi: $10.1016 /$ j.jphotochem.2019.111981

Li, H. T., Kang, Z. H., Liu, Y., and Lee, S. T. (2012). Carbon nanodots: synthesis, properties and applications. J. Mater. Chem. 22, 24230-24253. doi: $10.1039 / \mathrm{c} 2 \mathrm{jm} 34690 \mathrm{~g}$

Lim, S. Y., Shen, W., and Gao, Z. (2015). Carbon quantum dots and their applications. Chem. Soc. Rev. 44, 362-381. doi: 10.1039/C4CS00269E

Liu, C., Bao, L., Yang, M., Zhang, S., Zhou, M., Tang, B., et al. (2019). Surface sensitive photoluminescence of carbon nanodots: coupling between the carbonyl group and $\pi$-electron system. J. Phys. Chem. Lett. 10, 3621-3629. doi: 10.1021/acs.jpclett.9b01339

Liu, H., Sun, Y., Li, Z., Yang, R., Yang, J., Aryee, A. A., Zhang, X., Ge, J., Qu, L., and Lin, Y. (2019). SciFinder-guided rational design of fluorescent carbon dots for ratiometric monitoring intracellular $\mathrm{pH}$ fluctuations under heat shock. Chin. Chem. Lett. 30, 1647-1651. doi: 10.1016/j.cclet.2019.06.012

Liu, H. P., Ye, T., and Mao, C. D. (2007). Fluorescent carbon nanoparticles derived from candle soot. Angew. Chem. Int. Ed. 46, 6473-6475. doi: 10.1002/anie.200701271

Liu, X., Liu, J., Zheng, B., Yan, L., Dai, J., Zhuang, Z., Du, J., Guo, Y., and Xiao, D. (2017). N-Doped carbon dots: green and efficient synthesis on a large-scale and their application in fluorescent pH sensing. New J. Chem. 41, 10607-10612. doi: 10.1039/C7NJ01889D

Liu, X., Yang, C., Zheng, B., Dai, J., Yan, L., Zhuang, Z., Du, J., Guo, Y., and Xiao, D. (2018). Green anhydrous synthesis of hydrophilic carbon dots on large-scale and their application for broad fluorescent $\mathrm{pH}$ sensing. Sens. Actuator B Chem. 255, 572-579. doi: 10.1016/j.snb.2017.08.101

Lu, S., Cong, R., Zhu, S., Zhao, X., Liu, J., Tse, J. S., Meng, S., and Yang, B. (2016). pH-dependent synthesis of novel structure-controllable polymercarbon nanodots with high acidophilic luminescence and super carbon dots assembly for white light-emitting diodes. ACS Appl. Mater. Interfaces. 8, 4062-4068. doi: 10.1021/acsami.5b11579

Lv, W., Wang, X., Wu, J., Li, H., and Li, F. (2019). pH and $\mathrm{H}_{2} \mathrm{O}_{2}$ dual-responsive carbon dots for biocatalytic transformation monitoring. Chin. Chem. Lett. 30, 1635-1638. doi: 10.1016/j.cclet.2019.06.029

Mani, G. K., Miyakoda, K., Saito, A., Yasoda, Y., Kajiwara, K., Kimura, M., and Tsuchiya, K. (2017). Microneedle pH sensor: direct, label-free, real-time detection of cerebrospinal fluid and bladder pH. ACS Appl. Mater. Interfaces. 9, 21651-21659. doi: 10.1021/acsami.7b04225

Mondal, T. K., Mondal, S., Ghorai, U. K., and Saha, S. K. (2019). White light emitting lanthanide based carbon quantum dots as toxic $\mathrm{Cr}(\mathrm{VI})$ and $\mathrm{pH}$ sensor. J. Colloid Interface Sci. 553, 177-185. doi: 10.1016/j.jcis.2019.06.009

Pan, D., Zhang, J., Li, Z., Wu, C., Yan, X., and Wu, M. (2010b). Observation of pH-, solvent-, spin-, and excitation-dependent blue photoluminescence from carbon nanoparticles. Chem. Commun. 46, 3681-3683. doi: 10.1039/c000114g

Pan, D., Zhang, J., Li, Z., and Wu, M. (2010a). Hydrothermal route for cutting graphene sheets into blue-luminescent graphene quantum dots. Adv. Mater. Weinheim. 22, 734-738. doi: 10.1002/adma.200902825

Pyne, A., Layek, S., Patra, A., and Sarkar, N. (2019). An easy and smart way to explore the light- emitting responses of carbon dot and doxorubicin hydrochloride assembly: white light generation and $\mathrm{pH}$ - dependent reversible photoswitching. J. Mater. Chem. C. 7, 6414-6425. doi: 10.1039/C9TC01629E

Qiao, Z.-A., Wang, Y., Gao, Y., Li, H., Dai, T., Liu, Y., and Huo, Q. (2010). Commercially activated carbon as the source for producing multicolor photoluminescent carbon dots by chemical oxidation. Chem. Commun. 46, 8812-8814. doi: $10.1039 / \mathrm{c} 0 \mathrm{cc} 02724 \mathrm{c}$

Shen, J. H., Zhu, Y. H., Yang, X. L., and Li, C. Z. (2012). Graphene quantum dots: emergent nanolights for bioimaging, sensors, catalysis and photovoltaic devices. Chem. Commun. 48, 3686-3699. doi: 10.1039/c2cc00110a

Shi, L. H., Li, Y. Y., Li, X. F., Zhao, B., Wen, X. P., Zhang, G. M., Dong, C., and Shuang, S. M. (2016). Controllable synthesis of green and blue fluorescent carbon nanodots for $\mathrm{pH}$ and $\mathrm{Cu}^{2+}$ sensing in living cells. Biosens. Bioelectron. 77, 598-602. doi: 10.1016/j.bios.2015.10.031

Su, Q., Lu, C., and Yang, X. (2019). Efficient room temperature phosphorescence carbon dots: information encryption and dual-channel $\mathrm{pH}$ sensing. Carbon. 152, 609-615. doi: 10.1016/j.carbon.2019.06.061
Sui, L., Jin, W., Li, S., Liu, D., Jiang, Y., Chen, A., Liu, H., Shi, Y., Ding, D., and Jin, M. (2016). Ultrafast carrier dynamics of carbon nanodots in different $\mathrm{pH}$ environments. Phys. Chem. Chem. Phys. 18, 3838-3845. doi: 10.1039/C5CP07558K

Sun, Y., Wang, X., Wang, C., Tong, D., Wu, Q., Jiang, K., Jiang, Y., Wang, C., and Yang, M. (2018). Red emitting and highly stable carbon dots with dual response to $\mathrm{pH}$ values and ferric ions. Microchim. Acta. 185:83. doi: 10.1007/s00604-017-2544-1

Tan, J., Ye, Y., Ren, X., Zhao, W., and Yue, D. (2018). High pH-induced efficient room-temperature phosphorescence from carbon dots in hydrogen-bonded matrices. J. Mater. Chem. C. 6, 7890-7895. doi: 10.1039/C8TC02012D

Valeur, B. (2001). Molecular Fluorescence: Principles and Applications. Weinheim: Wiley-VCH.

Wang, C., Xu, Z., Cheng, H., Lin, H., Humphrey, M. G., and Zhang, C. (2015). A hydrothermal route to water-stable luminescent carbon dots as nanosensors for pH and temperature. Carbon 82, 87-95. doi: 10.1016/j.carbon.2014.10.035

Wang, L., Li, M., Li, W., Han, Y., Liu, Y., Li, Z., Zhang, B., and Pan, D. (2018). Rationally designed efficient dual-mode colorimetric/fluorescence sensor based on carbon dots for detection of $\mathrm{pH}$ and $\mathrm{Cu}^{2+}$ ions. ACS Sustainable Chem. Eng. 6, 12668-12674. doi: 10.1021/acssuschemeng.8b01625

Wang, Q., Yang, H., Zhang, Q., Ge, H., Zhang, S., Wang, Z., and Ji, X. (2019). Strong acid-assisted preparation of green-emissive carbon dots for fluorometric imaging of $\mathrm{pH}$ variation in living cells. Microchim. Acta. 186:468. doi: 10.1007/s00604-019-3569-4

Wang, T., Chen, G., Li, L., and Wu, Y. (2019). Highly fluorescent green carbon dots as a fluorescent probe for detecting mineral water pH. Sensors. 19:3801. doi: $10.3390 / \mathrm{s} 19173801$

Wang, W., Cheng, L., and Liu, W. (2014). Biological applications of carbon dots. Sci. China Chem. 57, 522-539. doi: 10.1007/s11426-014-5064-4

Wencel, D., Abel, T., and McDonagh, C. (2014). Optical chemical pH sensors. Anal. Chem. 86, 15-29. doi: 10.1021/ac4035168

Wu, Z. L., Gao, M. X., Wang, T. T., Wan, X. Y., Zheng, L. L., and Huang, C. Z. (2014). A general quantitative $\mathrm{pH}$ sensor developed with dicyandiamide $\mathrm{N}$ doped high quantum yield graphene quantum dots. Nanoscale 6, 3868-3874. doi: 10.1039/C3NR06353D

Xia, J., Chen, S., Zou, G.-Y., Yu, Y.-L., and Wang, J.-H. (2018). Synthesis of highly stable red-emissive carbon polymer dots by modulated polymerization: from the mechanism to application in intracellular $\mathrm{pH}$ imaging. Nanoscale 10, 22484-22492. doi: 10.1039/C8NR08208A

Xu, X., Ray, R., Gu, Y., Ploehn, H. J., Gearheart, L., Raker, K., and Scrivens, W. A. (2004). Electrophoretic analysis and purification of fluorescent singlewalled carbon nanotube fragments. J. Am. Chem. Soc. 126, 12736-12737. doi: $10.1021 / \mathrm{ja} 040082 \mathrm{~h}$

Xu, Z. Q., Lan, J. Y., Jin, J. C., Gao, T., Pan, L. L., Jiang, F. L., and Liu, Y. (2015). Mechanistic studies on the reversible photophysical properties of carbon nanodots at different pH. Colloid Surf. B Biointerfaces. 130, 207-214. doi: 10.1016/j.colsurfb.2015.04.012

Yang, P., Zhu, Z., Zhang, T., Zhang, W., Chen, W., Cao, Y., Chen, M., and Zhou, X. (2019). Orange-emissive carbon quantum dots: toward application in wound $\mathrm{pH}$ monitoring based on colorimetric and fluorescent changing. Small 15:e1902823. doi: 10.1002/smll.201902823

Ye, X., Xiang, Y., Wang, Q., Li, Z., and Liu, Z. (2019). A red emissive two-photon fluorescence probe based on carbon dots for intracellular $\mathrm{pH}$ detection. Small. 15:e1901673. doi: 10.1002/smll.201901673

Yin, J., Hu, Y., and Yoon, J. (2015). Fluorescent probes and bioimaging: alkali metals, alkaline earth metals and pH. Chem. Soc. Rev. 44, 4619-4644. doi: 10.1039/C4CS00275J

Yuan, F., Li, S., Fan, Z., Meng, X., Fan, L., and Yang, S. (2016). Shining carbon dots: synthesis and biomedical and optoelectronic applications. Nano Today 11, 565-586. doi: 10.1016/j.nantod.2016.08.006

Zhang, M., Su, R., Zhong, J., Fei, L., Cai, W., Guan, Q., Li, W., Li, N., Chen, Y., Cai, L., and Xu, Q. (2019). Red/orange dual-emissive carbon dots for $\mathrm{pH}$ sensing and cell imaging. Nano Res. 12, 815-821. doi: 10.1007/s12274-019-2293-Z

Zhang, Q. Q., Yang, T., Li, R. S., Zou, H. Y., Li, Y. F., Guo, J., Liu, X. D., and Huang, C. Z. (2018). A functional preservation strategy for the production of highly photoluminescent emerald carbon dots for lysosome targeting and lysosomal pH imaging. Nanoscale 10, 14705-14711. doi: 10.1039/C8NR03212B 
Zhang, T. Y., Dong, S., Zhao, F. F., Deng, M. X., Fu, Y. Q., and Lu, C. L. (2019). Tricolor emissive carbon dots for ultra-wide range $\mathrm{pH}$ test papers and bioimaging. Sens. Actuator B Chem. 298:126869. doi: 10.1016/j.snb.2019.126869

Zhao, C., Lia, X., Cheng, C., and Yang, Y. (2019). Green and microwave-assisted synthesis of carbon dots and application for visual detection of cobalt(II) ions and pH sensing. Microchem. J. 147, 183-190. doi: 10.1016/j.microc.2019. 03.029

Zhu, S. J., Meng, Q. N., Wang, L., Zhang, J. H., Song, Y. B., Jin, H., et al. (2013). Highly photoluminescent carbon dots for multicolor patterning, sensors, and bioimaging. Angew. Chem. Int. Ed. 52, 3953-3957. doi: 10.1002/anie.2013 00519

Zhu, S. J., Zhang, J. H., Qiao, C. Y., Tang, S. J., Li, Y. F., Yuan, W. J., et al. (2011). Stronglygreen-photoluminescent graphene quantum dots for bioimaging applications. Chem. Commun. 47, 6858-6860. doi: 10.1039/c1cc1 $1122 \mathrm{a}$

Conflict of Interest: The authors declare that the research was conducted in the absence of any commercial or financial relationships that could be construed as a potential conflict of interest.

Copyright (c) $2021 \mathrm{Liu}$, Zhang, Hu, Gao and Zhang. This is an open-access article distributed under the terms of the Creative Commons Attribution License (CC BY).

The use, distribution or reproduction in other forums is permitted, provided the original author(s) and the copyright owner(s) are credited and that the original publication in this journal is cited, in accordance with accepted academic practice. No use, distribution or reproduction is permitted which does not comply with these terms. 